\title{
Determination of Chlorinity of Water without the Use of Chromate Indicator
}

\author{
Tae-Kee Hong, ${ }^{1}$ Myung-Hoon Kim, ${ }^{2}$ and Myung-Zoon Czae ${ }^{3}$ \\ ${ }^{1}$ Department of Chemistry, Hanseo University, Seosan, Choongnam 139-743, Republic of Korea \\ ${ }^{2}$ Department of Sciences, Georgia Perimeter College, Dunwoody, GA 30338, USA \\ ${ }^{3}$ Department of Chemistry, Hanyang University, Seoul 133-791, Republic of Korea \\ Correspondence should be addressed to Myung-Hoon Kim, myung.kim@gpc.edu
}

Received 28 August 2010; Revised 14 November 2010; Accepted 8 December 2010

Academic Editor: John P. Hart

Copyright (๑) 2010 Tae-Kee Hong et al. This is an open access article distributed under the Creative Commons Attribution License, which permits unrestricted use, distribution, and reproduction in any medium, provided the original work is properly cited.

A new method for determining chlorinity of water was developed in order to improve the old method by alleviating the environmental problems associated with the toxic chromate. The method utilizes a mediator, a weak acid that can form an insoluble salt with the titrant. The mediator triggers a sudden change in $\mathrm{pH}$ at an equivalence point in a titration. Thus, the equivalence point can be determined either potentiometrically (using a pH meter) or simply with an acid-base indicator. Three nontoxic mediators (phosphate, EDTA, and sulfite) were tested, and optimal conditions for the sharpest $\mathrm{pH}$ changes were sought. A combination of phosphate (a mediator) and phenolphthalein (an indicator) was found to be the most successful. The choices of the initial pH and the concentration of the mediator are critical in this approach. The optimum concentration of the mediator is $c a$. $1 \sim 2 \mathrm{mM}$, and the optimum value of the initial $\mathrm{pH}$ is $c a .9$ for phosphate/phenolphthalein system. The method was applied to a sample of sea water, and the results are compared with those from the conventional Mohr-Knudsen method. The new method yielded chlorinity of a sample of sea water of $(17.58 \pm 0.22) \mathrm{g} / \mathrm{kg}$, which is about $2.5 \%$ higher than the value $(17.12 \pm 0.22) \mathrm{g} / \mathrm{kg}$ from the old method.

\section{Introduction}

Chlorinity is one of the most fundamental quantities associated with water quality $[1,2]$, and it is directly related to the salinity of sea water [3] and often used to determine the salinity [4]. In recent years, physical methods of determining salinity $[5,6]$, such as coulometry, measurements of conductivity, refractive index, or density, have become more popular because of their speed. Nevertheless, chemical measurements of chlorinity still remains an important and independent method of characterizing water quality. Various chemical methods have been reported for chlorinity determination: the gravimetric method with $\mathrm{AgCl}$ precipitates [7-9], various volumetric precipitation titrations with silver (I) or mercury (II) ions [7-9], and a recent spectroscopic method utilizing the Raman scattering band of $\mathrm{OH}$ stretching of water [10]. Among these chemical methods, the volumetric titrations with precipitation with $\mathrm{Ag}^{+}$have been most popular because it is less time consuming than the gravimetry. Several different ways of determining the equivalence point have been reported for the volumetric titrations with silver ion, such as (a) use of various visual indicators $[11,12]$, (b) thermometric titration measuring enthalpy changes [13], and (c) potentiometric titration [14]. The analytical methods recommended in the Standard Method for the Examination of Water and Waste Water [15] and the Official and Standardized Method of Analysis [16] are: (1) argentometric titration with silver nitrate using potassium chromate indicator, (2) titration with mercuric nitrate using s-diphenylcarbazone indicator, and (3) potentiometric titration using a glass and a silver-silver chloride electrode. The present work is aimed at improving the common volumetric method (1) of argentometric titration. However, the argentometry with the Mohr or Mohr-Knudsen method $[1,5,7]$, which is based on appearance of the red color of silver chromate precipitate at the equivalence point 


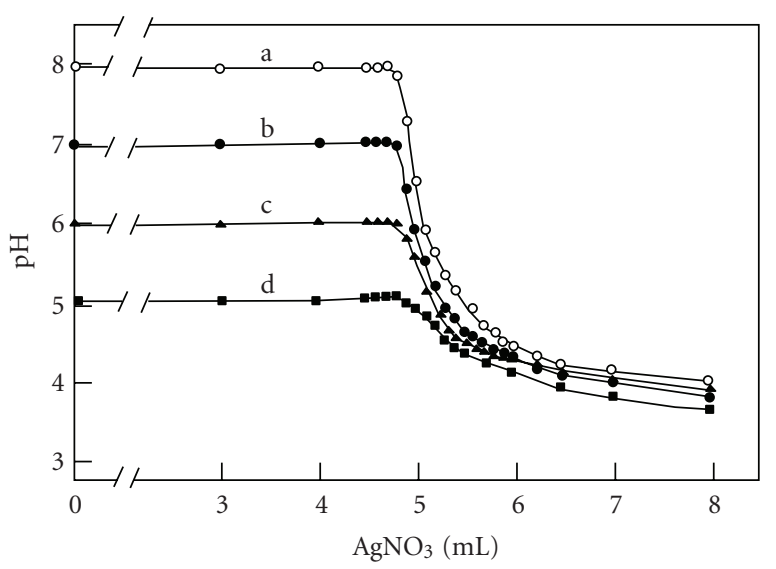

(a)

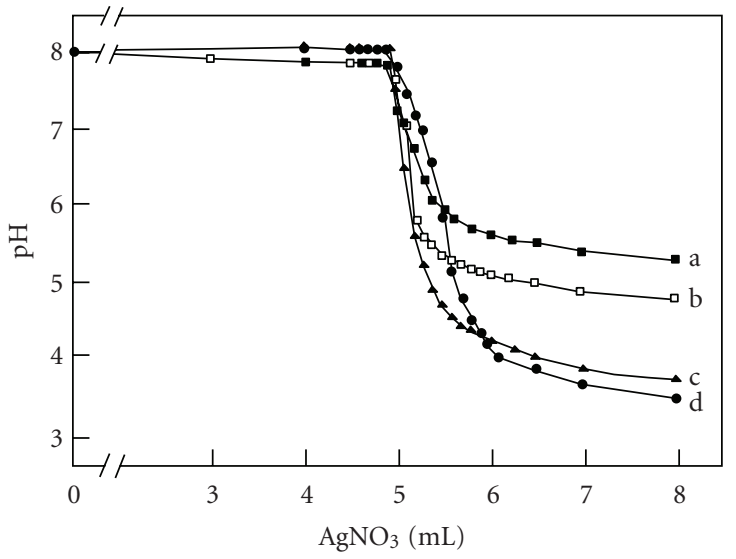

(b)

Figure 1: (a) Titration curves for $25.0 \mathrm{~mL}$ of $0.10 \mathrm{M} \mathrm{NaCl}$ with $0.50 \mathrm{M} \mathrm{AgNO}_{3}$ in the presence of $1.3 \mathrm{mM}$ phosphate at various starting pH values: (a) 7.9, (b) 7.0, (c) 6.0, and (d) 5.1. (b) Titration curves for $25.0 \mathrm{~mL}$ of $0.10 \mathrm{M} \mathrm{NaCl}$ with $0.50 \mathrm{M} \mathrm{AgNO}_{3}$ in the presence of various phosphate concentrations: (a) 0.05 , (b) 0.20 , (c) 2.0 , and (d) $6.0 \mathrm{mM}$.

raises concerns with environment problems because of the toxicity of the chromate with a hexavalent chromium.

Although trivalent chromium, $\mathrm{Cr}(\mathrm{III})$, is nontoxic, the acute and chronic toxicity and carcinogenicity of the hexavalent chromium, $\mathrm{Cr}(\mathrm{VI})$, have been well documented [17-19]. Thus, conversion of $\mathrm{Cr}(\mathrm{VI})$ to $\mathrm{Cr}(\mathrm{III})$ and speciation and fate of chromium in the environment and in model systems and kinetics of reduction of $\mathrm{Cr}(\mathrm{VI})$ have drawn much interest in recent years [20-25]. Chromium pollution in surface water is largely due to discharge from chemical plants where chromium is used in tanning leather, as a mordant in the textile industry, and in the galvanic process for anodizing aluminum in the aircraft industry and other industries. The current Maximum Contaminant Level (MCL) of chromium from the EPA (USA) is $100 \mathrm{ppb}$ (for water), and the Permissible Exposure Limit (PEL) from the OSHA (USA) is $52 \mu \mathrm{g} / \mathrm{m}^{3}$ (for air). The latter is much higher than a new proposed level of $1 \mu \mathrm{g} / \mathrm{m}^{3}$ [26]. Thus, it is desirable to reduce chromium discharge to environment in all possible ways. The toxicity of mercury is also well known [18]: thus, the method (2) is not a desirable one. With this in mind, we developed an environmentally more benign method for determining the chlorinity of water without using the hexavalent chromium or divalent mercury salt.

Changes in $\mathrm{pH}$ during certain types of precipitation titrations have long been observed [12, 27, 28], and the $\mathrm{pH}$ change can be made large enough so that an equivalence point can be determined either potentiometrically with a $\mathrm{pH}$ electrode or using acid-base indicators under suitable conditions. When reactions involve hydrolysis of a cation or an anion yielding a large $\mathrm{pH}$, an equivalence point can be detected potentiometrically [29-31]. A quantitative model to predict the $\mathrm{pH}$ change in such hydrolytic systems have been reported [32, 33]: Dobcnik and coworkers proposed a mathematical model for the titration of a metal ion $\left(\mathrm{Pb}^{2+}\right)$ with oxalate and other anions [34]. In their studies, after all of the lead is removed as lead oxalate precipitates at the equivalence point, the excess oxalate anions pick up $\mathrm{H}^{+}$from solution to form oxalic acid: this triggers a rapid increase in $\mathrm{pH}$. The equivalence point was determined to be a crossing point (i.e., the point at which two tangents on the two earlier sections of the titration curve intersect) [32-34]. Thus, the theory and practice of hydrolytic types of precipitation reaction have been established. A theory and practice for the precipitation titration that does not involve a hydrolysis, however, have not been well studied yet except in our recent report [35]. The argentometric titration of chloride per se does not involve hydrolysis of an anion or a cation because neither $\mathrm{Ag}^{+}$nor $\mathrm{Cl}^{-}$hydrolyses. Thus, very little change in $\mathrm{pH}(\Delta \mathrm{pH}<0.1)$ has been observed around an equivalence point during a titration of chloride ion with silver ion [27]. In the presence of various adsorption indicators, however, somewhat larger changes in $\mathrm{pH}$ have been observed [12, 28]; typically, $\Delta \mathrm{pH}$ is less than three units. This change is not large enough for an acid-base indicator to respond sharply at the equivalence point although it can be followed potentiometrically with a $\mathrm{pH}$ meter [36]. In our recent work [35], we have fully demonstrate, both in theory and practice, that the $\mathrm{pH}$ change at the equivalence point can be made sufficiently large even though the precipitation reaction does not involve hydrolysis. This was possible by introducing an additional reagent (chromate, a mediator) that undergoes hydrolysis so that the concentration of $\mathrm{H}^{+}$can be changed drastically at the equivalence point. Equivalence points were detected with a $\mathrm{pH}$ meter, which yielded less than $1 \%$ of relative errors that depend on the mediators [35]. For clarity, a brief comparison with the old Mohr method and current new method is presented below in terms of the reaction involved.

1.1. Comparison of the Current Approach with the Mohr Method. The Mohr method utilizes the formation of a red-colored precipitate of titrant $\left(\mathrm{Ag}^{+}\right)$with an indicator $\left(\mathrm{CrO}_{4}{ }^{-2}\right)$ (see (2)) after all thechloride is precipitated out of 


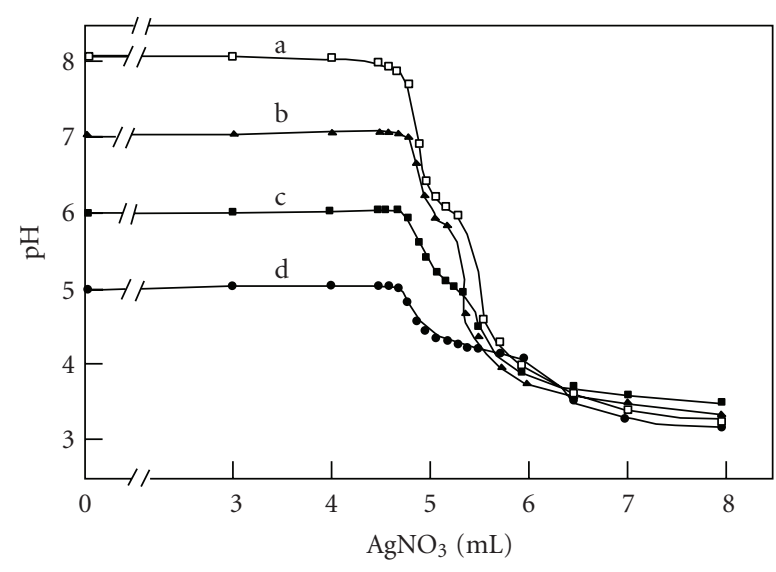

(a)

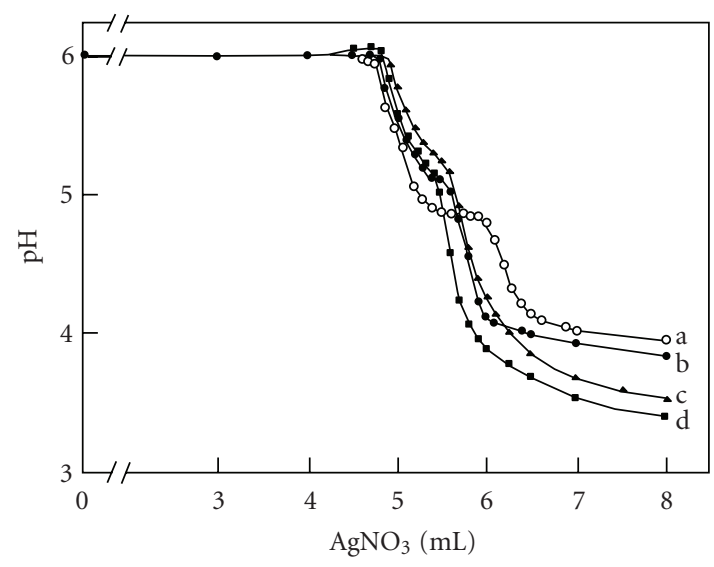

(b)

Figure 2: (a) Potentiometric titration curves for $25.0 \mathrm{~mL}$ of $0.10 \mathrm{M} \mathrm{NaCl}$ with $0.50 \mathrm{M} \mathrm{AgNO}_{3}$ in the presence of $3.2 \mathrm{mM}$ EDTA at various starting pH values: (a) 8.1, (b) 7.0, (c) 6.0, and (d) 5.0. (b) Titration curves for $25.0 \mathrm{~mL}$ of $0.10 \mathrm{M} \mathrm{NaCl} \mathrm{with} 0.50 \mathrm{M} \mathrm{AgNO}_{3}$ at various concentrations of EDTA: (a) 0.70, (b) 3.2, (c) 6.3, and (d) $14.2 \mathrm{mM}$.

the solution by $\mathrm{Ag}^{+}$(see (1)) at the equivalence point

$$
\begin{array}{r}
\mathrm{Cl}^{-}+\mathrm{Ag}^{+} \leftrightarrows \mathrm{AgCl}(\mathrm{s}) \text { (white) } \\
\mathrm{CrO}_{4}^{-2} \text { (yellow) }+2 \mathrm{Ag}^{+} \leftrightarrows \mathrm{Ag}_{2} \mathrm{CrO}^{4}(\mathrm{~s}) \text { (red) } \\
\text { Indicator reaction }
\end{array}
$$

The appearance of the red precipitate of silver chromate signals the end point of the titration. This method has been particularly useful in the determination of chlorinity $[1,4,37]$ in samples of sea water.

In the current method [35], a weak acid (HA) whose conjugate base $\left(A^{-}\right)$can form a slightly soluble salt (AgA) with the titrant $\left(\mathrm{Ag}^{+}\right)$is added in place of the visual indicator (chromate) above; this allows equivalence point to be detected either with a $\mathrm{pH}$ electrode [35] or with an acid-base indicator. The acid (HA) or its conjugate base $\left(\mathrm{A}^{-}\right)$acts as a mediator (or as an indicator) so that $\mathrm{HA}$ can release $\mathrm{H}^{+}$ when the equivalent point is reached. This system presents an equilibrium problem in which an acid-base reaction is coupled to two solubility equilibria, resulting in four coupled equilibria including the ionization of water (see (6))

$$
\begin{gathered}
\mathrm{Cl}^{-}+\mathrm{Ag}^{+} \leftrightarrows \mathrm{AgCl}(\mathrm{s})\left(\text { white) } \quad \mathrm{K}_{\mathrm{sp}}=\left[\mathrm{Ag}^{+}\right]\left[\mathrm{Cl}^{-}\right]\right. \\
\mathrm{HA} \leftrightarrows \mathrm{H}^{+}+\mathrm{A}^{-} \quad \mathrm{K}_{\mathrm{a}}=\frac{\left[\mathrm{H}^{+}\right]\left[\mathrm{A}^{-}\right]}{[\mathrm{HA}]} \\
\mathrm{A}^{-}+\mathrm{Ag}^{+} \leftrightarrows \mathrm{AgA}(\mathrm{s}) \quad \mathrm{K}_{\mathrm{sp}}^{\prime}=\left[\mathrm{Ag}^{+}\right]\left[\mathrm{A}^{-}\right] \\
\mathrm{H}_{2} \mathrm{O} \leftrightarrows \mathrm{H}^{+}+\mathrm{OH}^{-} \\
\mathrm{K}_{\mathrm{w}}=\left[\mathrm{H}^{+}\right]\left[\mathrm{OH}^{-}\right]
\end{gathered}
$$

If the solubility of $\mathrm{AgCl}$ is less than that of $\mathrm{AgA}, \mathrm{AgCl}$ will be precipitated out first. After all the $\mathrm{Cl}^{-}$is removed, then additional $\mathrm{Ag}^{+}$will react with $\mathrm{A}^{-}$to remove it as a precipitate (AgA). As $\mathrm{A}^{-}$is being removed, HA must dissociate to replenish $\mathrm{A}^{-}$, thereby generating $\mathrm{H}^{+}$. Therefore, the $\mathrm{pH}$ of the system decreases at the equivalence point [35].
In this present work, we searched for the best nontoxic mediator and the best conditions that can bring a larger and sharper $\mathrm{pH}$ change so that even a common acid-base indicator can be employed in detecting an equivalence point for the titration. It is demonstrated that equivalence point is determined by using a nontoxic mediator (phosphate) and an acid-base indicator(phenolphthalein) without using a pH meter. This new approach is successfully applied for a determination of chlorinity of a sample of sea water.

\section{Experimental}

2.1. Reagent and Apparatus. All chemicals used were analytical reagent grade and were used without further purification. All solutions were prepared with deionized water. $\mathrm{AgNO}_{3}$ solutions were standardized using the Mohr method [7-9]. $\mathrm{pH}$ values were measured with a Fisher Accumet Selective Ion Analyzer Model $750 \mathrm{pH}$ Meter and an Orion Model 810 Digital pH Meter. Glass electrodes of Orion Model-91 series and a similar type of combination electrodes were used for the $\mathrm{pH}$ measurements. Initial $\mathrm{pHs}$ were adjusted by adding $0.10 \mathrm{M} \mathrm{NaOH}$ or $0.1 \mathrm{M} \mathrm{HCl}$. Solutions were stirred magnetically during titration.

\section{Results and Discussion}

Figure 1(a) presents titration curves for $25.0 \mathrm{~mL}$ of $0.10 \mathrm{M}$ $\mathrm{NaCl}$ with $0.50 \mathrm{M} \mathrm{AgNO}_{3}$ in the presence of a mediator (1.3 mM phosphate) at various $\mathrm{pH}$ values of 7.9, 7.0, 6.0, and 5.1. As predicted from the theory, the curves have same pattern as Figure 3(a) in [35]. At the highest initial $\mathrm{pH}$ values, the change in $\mathrm{pH}$ is the most with $3.9 \mathrm{pH}$ units, and at the lowest initial $\mathrm{pH}$, the change is the smallest with 1.4 $\mathrm{pH}$ units. The $\mathrm{pH}$ changes are summarized in Table 1. The crossing points for all the curves occurred somewhat earlier than the equivalence point.

Figure $1(\mathrm{~b})$ presents titration curves for the same solutions at various phosphate concentrations $(0.05,0.20,2.0$, 


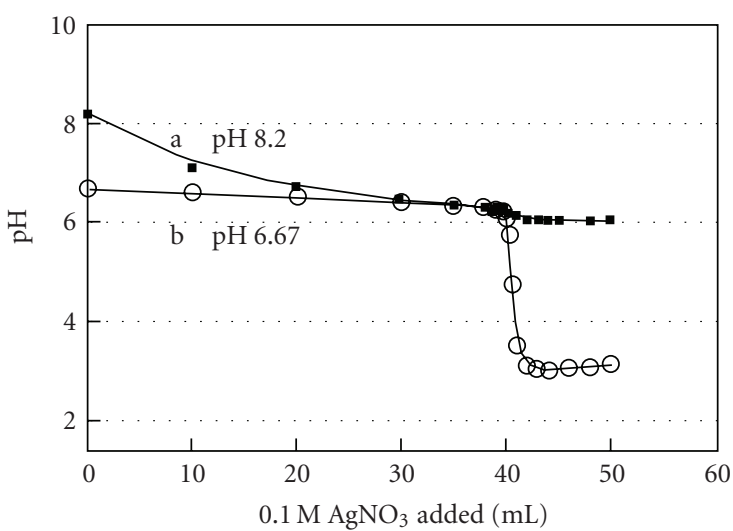

(a)

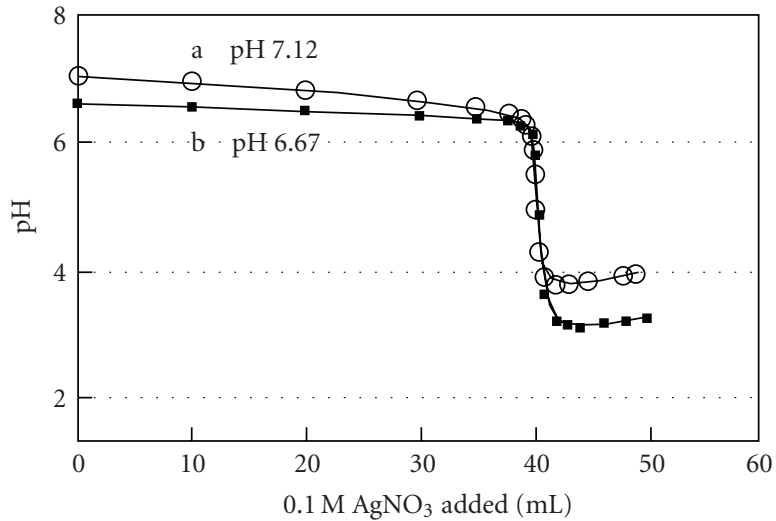

(b)

Figure 3: (a) Titration curves of $40.00 \mathrm{~mL}$ of $0.1 \mathrm{M} \mathrm{NaCl}$ with a $0.1 \mathrm{M} \mathrm{AgNO}_{3}$ solution at two different bisulfite concentrations: (a) $0.50 \mathrm{mM}$ $\left(\boldsymbol{\square}\right.$, initial pH 8.20), (b) $5.0 \mathrm{mM}\left(\bigcirc\right.$, initial pH 6.67). (b) Titration curves of $40.00 \mathrm{~mL}$ of $0.1 \mathrm{M} \mathrm{NaCl}$ with a $0.1 \mathrm{M} \mathrm{AgNO}_{3}$ solution in the presence of $5.0 \mathrm{mM}$ bisulfite at two different initial $\mathrm{pH}$ values: (a) $7.12(\bigcirc)$, (b) 6.67 ( $\mathbf{\square})$.

TABLE 1: Change in $\mathrm{pH}$ at various values of initial $\mathrm{pH}$ with $\mathrm{Na}_{2} \mathrm{HPO}_{4}$.

\begin{tabular}{lcc}
\hline Initial $\mathrm{pH}$ & $\mathrm{pH}$ range & $\Delta \mathrm{pH}$ \\
\hline 5.1 & $5.1-3.7$ & 1.4 \\
6.0 & $6.0-3.8$ & 2.2 \\
7.0 & $7.0-3.9$ & 3.1 \\
7.9 & $7.9-4.0$ & 3.9 \\
\hline
\end{tabular}

TABLE 2: Change in $\mathrm{pH}$ at various concentrations of $\mathrm{Na}_{2} \mathrm{HPO}_{4}$.

\begin{tabular}{lcc}
\hline Concentartion $(\mathrm{mM})$ & $\mathrm{pH}$ range & $\Delta \mathrm{pH}$ \\
\hline 0.05 & $7.8-5.4$ & 2.4 \\
0.20 & $7.8-4.8$ & 3.0 \\
2.0 & $8.0-3.8$ & 4.2 \\
5.0 & $8.0-3.6$ & 4.4 \\
\hline
\end{tabular}

and $6.0 \mathrm{mM}$ ). Again, the pattern resembles those predicted from the theory [35]. The crossing points for all the curves occur very close to the equivalence points. At lower mediator concentration, the change in $\mathrm{pH}$ is less $(\Delta \mathrm{pH}=2.5$ with curve (a)), and at higher mediator concentration the change is the largest $(\Delta \mathrm{pH}=4.4$ with curve $(\mathrm{d}))$. Table 2 summarize the $\mathrm{pH}$ change at various concentration of the mediator.

Figure 2(a) presents titration curves for the same solutions with another mediator, $3.2 \mathrm{mM}$ EDTA, at various starting pH values: (a) 8.1, (b) 7.0, (c) 6.0, and (d) 5.0. Although it exhibits the general trend, there are breaks in the curves. At the higher $\mathrm{pH}$ (8.1 and 7.0), $\mathrm{HY}^{3-}$ is dominant, and at the lower $\mathrm{pH}\left(5.0\right.$ and 6.0), $\mathrm{H}_{2} \mathrm{Y}^{2-}$ is dominant at the beginning. The one begun at 8.1 yielded the largest $\mathrm{pH}$ change. The narrow middle plateau for the curves (a)-(d), where the $\mathrm{pH}$ change becomes gradual again, is attributed to the conversion of either $\mathrm{HY}^{3-}$ to $\mathrm{H}_{2} \mathrm{Y}^{2-}$ or $\mathrm{H}_{2} \mathrm{Y}^{2-}$ to $\mathrm{H}_{3} \mathrm{Y}^{-}$. The crossing point occurred at about $4.7 \mathrm{~mL}$, which is about $6 \%$ error from the equivalence point. Thus, in the case of EDTA; however, the inflection points at about $4.9 \mathrm{~mL}$ appear to be a better equivalence point (with $2 \%$ of error) than the crossing point.

Figure 2(b) presents titration curves for the same solutions at various EDTA concentrations ranging from 0.7 (a) $-6.3 \mathrm{mM}$ (d). The one with the highest concentration $(6.3 \mathrm{mM})$ yielded the largest $\mathrm{pH}$ change. The crossing point for all curves has an error of 6\%. Thus, as in Figure 2(b), the inflection point appears to be a better equivalence point than the crossing points. Thus, EDTA does appear to be a good mediator in determining an equivalent point with the crossing point method.

All the previous experiments were performed as rather crude qualitative pilot runs using $0.50 \mathrm{M} \mathrm{AgNO}_{3}$. However, the following titrations (Figures 3 and 4 ) are aimed at obtaining more accurate quantitative results by using $0.10 \mathrm{M} \mathrm{AgNO}_{3}$ instead of $0.50 \mathrm{M} \mathrm{AgNO}_{3}$, and by increasing volumes of titrand $\left(\mathrm{Cl}^{-}\right)$from $25.0 \mathrm{~mL}$ to $40.0 \mathrm{~mL}$. Typical titration curves of $40.0 \mathrm{~mL}$ of $0.1 \mathrm{M} \mathrm{NaCl}$ with a $0.1 \mathrm{M}$ $\mathrm{AgNO}_{3}$ solution in the presence of $\mathrm{NaHSO}_{3}$ (the mediator) are presented in Figure 3(a) at two different concentrations of bisulfite: (a) $0.50 \mathrm{mM}(\boldsymbol{\square}$, initial $\mathrm{pH}$ of 8.2$)$ and (b) $5.0 \mathrm{mM}$ $(\bigcirc$, initial $\mathrm{pH}$ of 6.67).

The two results from the two concentrations are very different. The one obtained at $5.0 \mathrm{mM}$ bisulfite generated a curve with a well-defined equivalence point. Meanwhile, the one with a bisulfite concentration of $0.5 \mathrm{mM}$ generated a gradual $\mathrm{pH}$ change from the beginning without any break in $\mathrm{pH}$ changes, thus failing to produce a measurable crossing point. This illustrates the importance of controlling the concentration of the mediator and initial $\mathrm{pH}$ values. At the lower mediator concentration $(0.5 \mathrm{mM})$, most of the bisulfite exists in the fully deprotonated form $\left(\mathrm{SO}_{3}{ }^{2-}\right)$ at the $\mathrm{pH}$ of 8.2. Therefore, consumption of the sulfite by $\mathrm{Ag}^{+}$cannot drive a reaction $\left(\mathrm{HSO}_{3}{ }^{-} \rightarrow \mathrm{H}^{+}+\mathrm{SO}_{3}{ }^{2-}\right)$ to release much $\mathrm{H}^{+}$. Similar results of gradual $\mathrm{pH}$ change at the equivalence point, without any sharp break, were observed when $\mathrm{NaCN}$ was used as a mediator.

Figure 3(b) shows titrations in the presence of $5.0 \mathrm{mM}$ bisulfite at two different initial $\mathrm{pH}$ values ((a) 7.12, and 


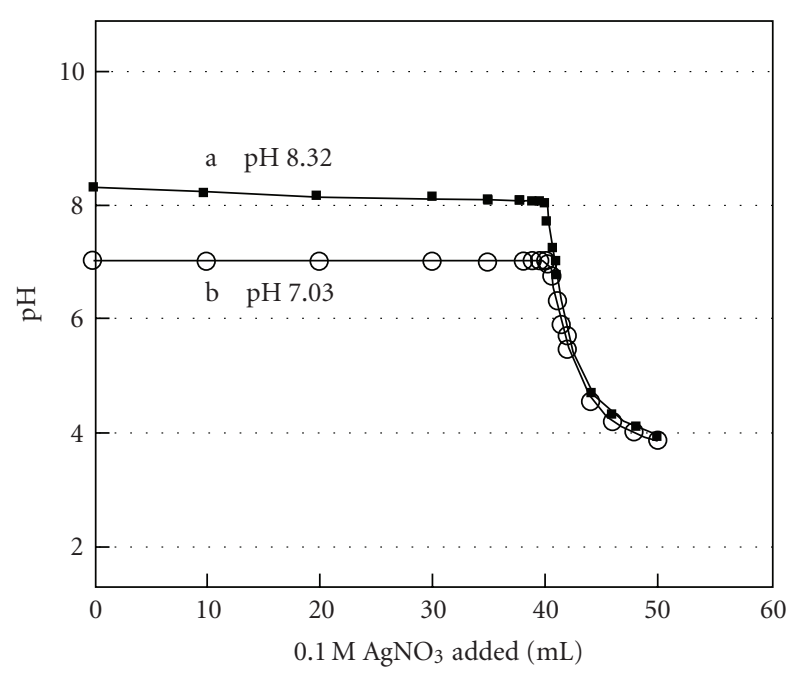

FIgUre 4: Titration curves of $40.0 \mathrm{~mL}$ of $0.1 \mathrm{M} \mathrm{NaCl}$ with a $0.1 \mathrm{M}$ $\mathrm{AgNO}_{3}$ solution in the presence of $2.5 \mathrm{mM} \mathrm{Na} 2 \mathrm{HPO}_{4}$ at two different initial $\mathrm{pH}$ values: (a) $8.32(\boldsymbol{\square})$ and (b) $7.03(\bigcirc)$.

(b) 6.67). Both yielded comparably good crossing points. A suitable range of initial $\mathrm{pH}$ values lies around 6 and 7 . When several mM of $\mathrm{NaHSO}_{3}$ are added, as a mediator, the initial $\mathrm{pH}$ of the solution will be in the right range, thus adjustment of $\mathrm{pH}$ at the beginning is not necessary. However, when $\mathrm{H}_{2} \mathrm{SO}_{3}$ is added as a mediator, it will be acidic $(\mathrm{pH} \sim 2)$ at the beginning; hence, a small amount of base $(0.1 \mathrm{M} \mathrm{NaOH})$ must be added to reach the optimum $\mathrm{pH}$ range. If $\mathrm{Na}_{2} \mathrm{SO}_{3}$ is used, the solution will be alkaline $(\mathrm{pH} \sim 9)$; therefore, an acid solution $\left(0.1 \mathrm{M} \mathrm{HNO}_{3}\right)$ should be added to bring $\mathrm{pH}$ value of the alkaline solution down to a range of $6 \sim 7$. Optimum concentration of the mediator was found to be in the range of $2 \sim 5 \mathrm{mM}$ : a lower concentration of the mediator generates a small and gradual change in $\mathrm{pH}$, while a higher concentration will generate less sharp changes in $\mathrm{pH}$ at the end point yielding a larger error. It is not clear why the $\mathrm{pH}$ increases again after equivalence point (after $41 \mathrm{~mL}$ ).

Figure 4 shows titration curves of $40.0 \mathrm{~mL}$ of $0.1 \mathrm{M} \mathrm{NaCl}$ with a $0.1 \mathrm{M} \mathrm{AgNO}_{3}$ solution in the presence of $2.5 \mathrm{mM}$ $\mathrm{Na}_{2} \mathrm{HPO}_{4}$ at two different initial pH values: (a) 8.32 and $(b) 7.03(\bigcirc)$. Even though the titration with the higher initial $\mathrm{pH}$ yielded a larger and sharper $\mathrm{pH}$ change, both results were comparably good. Table 3 presents results with phosphate at several different conditions. The crossing point method yielded much better results (an average of $0.1 \%$ relative error) than the inflection methods.

Finally, we applied the present method with an acidbase indicator to determine the chlorinity of a sample of sea water, and we compared the results of this method with the results from the Mohr-Knudsen Method. The phosphate was adopted as a mediator; phenolphthalein was employed as a visual indicator. The results are summarized in Table 4 . Five trials were made; the average and standard deviation values were $\left(17.12_{4} \pm 0.22_{4}\right) \mathrm{g} / \mathrm{kg}$ from the Mohr-Knudsen method and $\left(17.58_{4} \pm 0.21_{9}\right) \mathrm{g} / \mathrm{kg}$ from the present method. The average chlorinity from the mediator method was about $2.5 \%$ higher than that from the conventional method; the
TABLE 3: Errors in determining equivalence point: volume $(\mathrm{mL})$ of $\mathrm{Ag}^{+}$required using $\mathrm{Na}_{2} \mathrm{HPO}_{4}$.

\begin{tabular}{lcccc}
\hline Trial & $\begin{array}{c}\text { Mediator } \\
(\mathrm{mM})\end{array}$ & $\begin{array}{c}\text { Initial. } \\
\mathrm{pH}\end{array}$ & $\begin{array}{c}\text { Crossing } \\
\text { Point }\end{array}$ & $\begin{array}{c}\text { Inflection } \\
\text { Point }\end{array}$ \\
\hline 1 & 1.25 & 8.10 & 40.0 & 41.5 \\
2 & 1.25 & 8.10 & 39.9 & 41.5 \\
3 & 2.50 & 8.32 & 40.0 & 41.1 \\
4 & 2.50 & 7.20 & 39.9 & 41.1 \\
5 & 2.50 & 7.10 & 40.0 & 41.7 \\
6 & 2.50 & 7.00 & 40.0 & 41.7 \\
\hline Average of & & & $0.1 \%$ & $3 \%$ \\
Rel. Error & & & & \\
\hline
\end{tabular}

TABLE 4: Comparison of the Results of Determination of Chlorinity $(\mathrm{g} / \mathrm{kg})$ from the Mohr-Knudsen Method and the Present Methods with Phosphate/Phenolphthalein as Indicator.

\begin{tabular}{lccc}
\hline Trial & $\begin{array}{c}\text { Mohr-Knudsen } \\
\text { Method }\end{array}$ & $\begin{array}{c}\text { Phosphate/Ph'pht } \\
\text { Method (Present) }\end{array}$ & Difference \\
\hline 1 & 17.06 & 17.42 & 0.38 \\
2 & 17.00 & 17.32 & 0.32 \\
3 & 16.85 & 17.87 & 1.02 \\
4 & 17.36 & 17.61 & 0.05 \\
5 & 17.35 & 17.70 & 0.35 \\
\hline Ave. \pm & $17.12 \pm 0.22$ & $17.58 \pm 0.22$ \\
Std.Dev. & & \\
\hline
\end{tabular}

precision is about the same for both methods. The $F$ test and $t$-test yielded $F=0.9559(<6.39), t=3.31$, respectively, suggesting that the two standard deviations do not differ, but the results (chlorinities) are different somewhat $(2.5 \%)$. The higher value observed with the new method may be explained from the fact that the new method involves equilibrium (2), instead of equilibrium (1) in the old method: the additional equilibrium reaction may have required more $\mathrm{Ag}^{+}$for a complete shift of the equilibrium reaction to the right. Both values of the chlorinity of the sample (collected at the Western Sea of South Korea) are about $1 \%$ lower than that of an average chlorinity of sea water which is $19 \mathrm{~g} / \mathrm{kg}[38,39]$ that depends on a location of sampling.

\section{Summary}

A new method for determining chlorinity of water without using the chromate indicator was developed and successfully applied to determine chlorinity of sea water. Among the mediators tested, the phosphate in combination with phenolphthalein yielded the best result. Concentration of a mediator and the initial $\mathrm{pH}$ of the solution found to be critical for the success. Higher mediator concentrations yielded less accurate results even though they gave larger changes in $\mathrm{pH}$. At lower mediator concentration, the end point is more accurate, but $\mathrm{pH}$ change is not large enough for the visual indicator to bring a sharp color change. Thus, optimum concentration of the phosphate mediator appears 
to be in a range of $1 \sim 2 \mathrm{mM}$. The $\mathrm{pH}$ of the analyte solution must be adjusted initially to the alkaline side $(\mathrm{pH} 8.5$ or higher) so that phenolphthalein imparts a pink color at the beginning of the titration. Chlorinity of a sample of sea water from this method found to be $(17.58 \pm 0.22) \mathrm{g} / \mathrm{kg}$, which is about $2.5 \%$ higher than that $(17.12 \pm 0.22) \mathrm{g} / \mathrm{kg}$ from the conventional Mohr-Knudsen method. This new method may replace the argentometric titration with chromate indicator in the standard method [15] of determining chloride in water and waste water.

\section{Acknowledgments}

A grant from the Writer's Institute (GPC) is much appreciated. The authors thank Maureen Burkart for correcting and editing the paper.

\section{References}

[1] D. F. Martin, "Marine chemistry," in Analytical Methods, vol. 1, p. 65, Marcell Dekker, New York, NY, USA, 1968.

[2] A. H. Brownlow, Geochemistry, Prentice-Hall, Englewood Cliff, NJ, USA, 1979.

[3] T. R. S. Wilson, "Salinity and major elements of sea water," in Chemical Oceanography, J. P. Riley and G. Skirrow, Eds., chapter 6, Academic Press, New York, NY, USA, 2nd edition, 1975.

[4] R. A. Cox, "The physical properties of sea water," in Chemical Oceanography, J. P. Riley and G. Skirrow, Eds., vol. 1, chapter 3, Academic Press, London, UK, 1965.

[5] K. Grasshoff, "Determination of salinity," in Methods of Sea Water Analysis, K. Grasshoff, M. Ehrhardt, and K. Kremling, Eds., p. 31, Wiley-VCH, Weinheim, Germany, 1983.

[6] F. Millero and M. L. Sohn, Chemical Oceanography, chapter 2, CRC Press, Boca Raton, Fla, USA, 1996

[7] I. M. Kolthoff and E. B. Sandell, Textbook of Quantitative Inorganic Analysis, MacMillan, New York, NY, USA, 1969.

[8] D. C. Harris, Quantitative Chemical Analysis, W. H. Freeman \& Co., New York, NY, USA, 1982.

[9] R. A. Day and A. L. Underwood, Quantitative Analysis, Prentice Hall, New York, NY, USA, 5th edition, 1986.

[10] J. Dubessy, T. Lhomme, M. C. Boiron, and F. Rull, "Determination of chlorinity in aqueous fluids using Raman spectroscopy of the stretching band of water at room temperature: application to fluid inclusions," Applied Spectroscopy, vol. 56, no. 1, pp. 99-106, 2002.

[11] H. A. Laitenen, Chemical Analysis, chapter 12-13, McGraw Hill, New York, NY, USA, 1960.

[12] E. Pungor and E. Schulek, "Adsorption indicators," in Indicators, E. Bishop, Ed., chapter 7, Pergamon Press, Oxford, UK, 1972.

[13] F. J. Millero, S. R. Schrager, and L. D. Hansen, "Thermometric titration analysis of seawater for chlorinity, sulfate and alkalinity," Limnology and Oceanography, vol. 19, pp. 711-715, 1974.

[14] D. Jagner, "Potentiometric titrations," in Marine Electrochemistry, M. Whitfield and D. Jagner, Eds., chapter 7, John Wiley \& Sons, Chishester, UK, 1981.

[15] L. S. Clesceri, A. E. Greenberg, and A. D. Eaton, Standard Methods for the Examination of Water and Wastewater, American Public Health Association, America Water Works Association, Water Environment Federation, Washington, DC, USA, 29th edition, 1998.
[16] "Official and standardized method of analysis," in Analytical Methods Committee, C. A. Watson, Ed., p. 556, Royal Society of Chemistry, Cambridge, UK, 1994.

[17] Committee on Biological Effects of Atmospheric Pollutants, Chromium: Medical and Biological Effects of Environmental Pollutants, National Academy of Science, Washington, DC, USA, 1974.

[18] R. A. Goyer, "Toxic effects of metals," in Casarett and Doul's Toxicology, C. D. Klaassen, M. O. Amdur, and J. Doull, Eds., pp. 582-635, Macmillian, New York, NY, USA, 3rd edition, 1986.

[19] R. A. Anderson, "Essentiality of chromium in humans," Science of the Total Environment, vol. 86, no. 1-2, pp. 75-81, 1989.

[20] J. M. Eckert, J. J. Stewart, T. D. Waite, R. Szymczak, and K. L. Williams, "Reduction of chromium(VI) at sub- $\mu \mathrm{g} 1^{-1}$ levels by fulvic acid," Analytica Chimica Acta, vol. 236, no. 2, pp. 357362, 1990.

[21] F. C. Richard and A. C. M. Bourg, "Aqueous geochemistry of chromium: a review," Water Research, vol. 25, no. 7, pp. 807816, 1991.

[22] B. Deng and A. T. Stone, "Surface-catalyzed chromium(VI) reduction: reactivity comparisons of different organic reductants and different oxide surfaces," Environmental Science and Technology, vol. 30, no. 8, pp. 2484-2494, 1996.

[23] C.-J. Lin, "The chemical transformations of chromium in natural waters-a model study," Water, Air, and Soil Pollution, vol. 139, no. 1-4, pp. 137-158, 2002.

[24] M. Pettine, L. D’Ottone, L. Campanella, F. J. Millero, and R. Passino, "The reduction of chromium (VI) by iron (II) in aqueous solutions," Geochimica et Cosmochimica Acta, vol. 62, no. 9, pp. 1509-1519, 1998.

[25] M. Pettine, D. Tonnina, and F. J. Millero, "Chromium(VI) reduction by sulphur(IV) in aqueous solutions," Marine Chemistry, vol. 99, no. 1-4, pp. 31-41, 2006.

[26] D. Michaels, C. Monforton, and P. Lurie, "Selected science: an industry campaign to undermine an OSHA hexavalent chromium standard," Environmental Health, vol. 5, article no. 5, p. 8, 2006.

[27] M.-Z. Czae, "The adsorption of hydrogen and hydroxyl ions during precipitation tritration," Journal of the Korean Chemical Society, vol. 14, no. 1, p. 137, 1970.

[28] L. Legradi, "Az adszorpcios indikacio mechanizmusa," Magyar Kemiai Folyoirat, vol. 76, no. 1, pp. 30-40, 1970 (Hungarian).

[29] N. Hota, "Use of a $\mathrm{pH}$ meter for indicating the end point of the precipitation titration of sulfate with a mixed solution of barium nitrate and lead nitrate," Bunseki Kagaku, vol. 19, p. 780, 1970.

[30] N. Hota, "Use of a $\mathrm{pH}$ meter for indicating the end point of the precipitometry. II. Titration of halides, iodate, chromate, and secondary phosphate," Bunseki Kagaku, vol. 20, p. 522, 1971.

[31] N. Hota, " $\mathrm{pH}$ meter for indicating the end point of various titrations in mixed solvent. Precipitometry using a titrant of silver nitrate, lead nitrate, sodium sulfide and neutralization titration of ammonium compounds,"Bunseki Kagaku, vol. 21, p. 1463,1972 .

[32] D. Dobčnik and D. Brodnjak-Vončina, "Hydrolytic potentiometric titration of sulphate with application in the analysis of waters," Analytica Chimica Acta, vol. 177, pp. 209-212, 1985.

[33] D. Dobčnik and J. Gibicar, Vestnik Slovenskega Kemijskega Drustva, vol. 34, p. 305, 1987. 
[34] D. Brodnjak Voncina, D. Dobcnik, and G. Gomiscek, "Hydrolytic precipitation titrations followed by a glass electrode," Analytica Chimica Acta, vol. 263, no. 1-2, pp. 147-153, 1992.

[35] T.-K. Hong, B.-H. Koo, M.-H. Kim, and M.-Z. Czae, "Use of $\mathrm{pH}$ electrode for precipitation titration analysis: theory and practice," Journal of Analytical Chemistry, vol. 64, p. 1158, 2009.

[36] J. F. Coetzee, "Precipitation equilibria and titrations in aqueous and non-aqueous media," in Treatise on Analytical Chemistry, I. M. Kolthoff and P. J. Elving, Eds., vol. 3, pp. 370378, John Wiley \& Sons, New York, NY, USA, 1983.

[37] J. P. Riley, in Chemical Oceanography, J. P. Riley and G. Skirrow, Eds., chapter 21, Academic Press, New York, NY, USA, 1965.

[38] R. A. Berner, "Activity coefficients of bicarbonate, carbonate and calcium ions in sea water," Geochimica et Cosmochimica Acta, vol. 29, no. 8, pp. 947-965, 1965.

[39] G. S. Sodhi, Fundamental Concepts of Environmental Chemistry, Alpha Science International, 2000. 


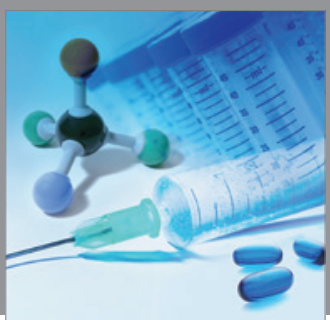

International Journal of

Medicinal Chemistry

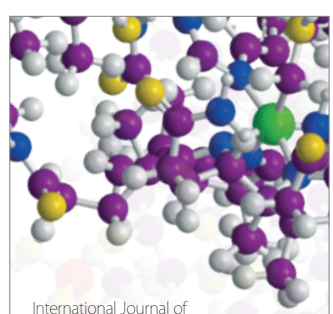

Carbohydrate Chemistry

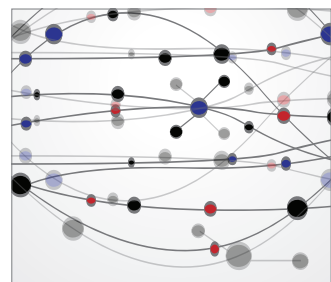

The Scientific World Journal
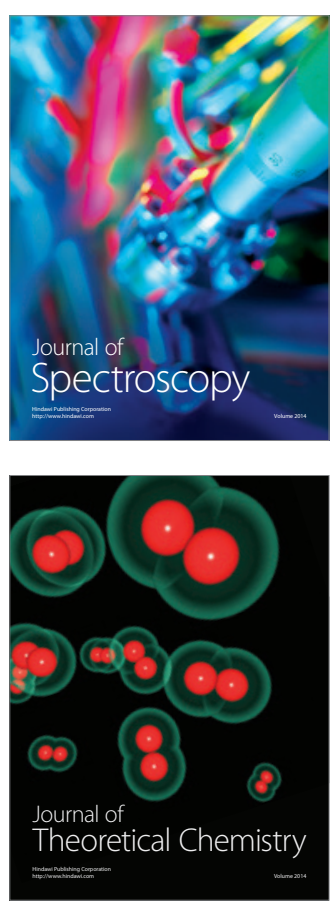
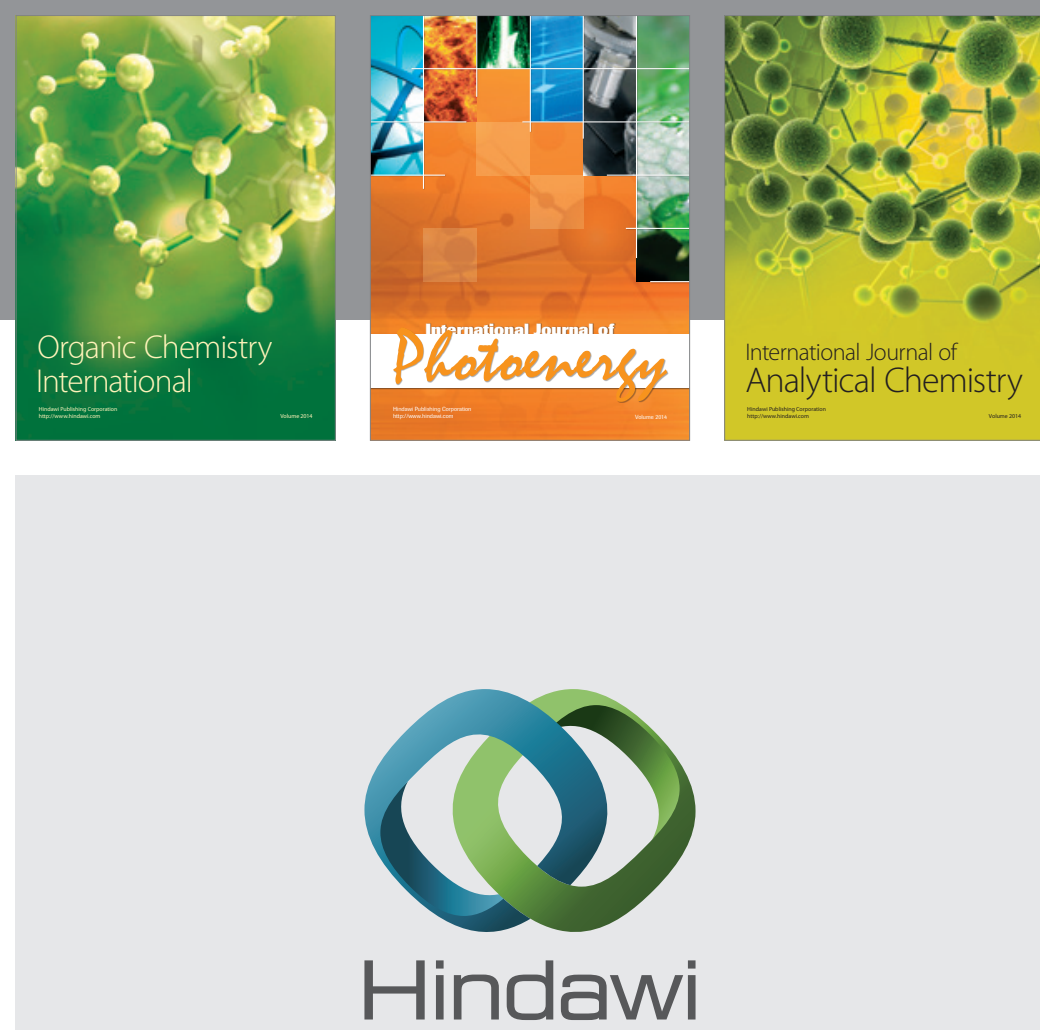

Submit your manuscripts at

http://www.hindawi.com
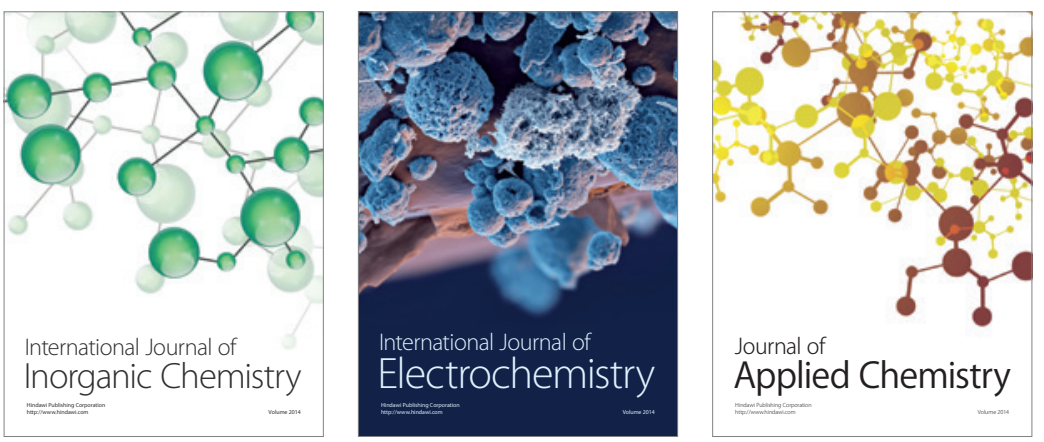

Journal of

Applied Chemistry
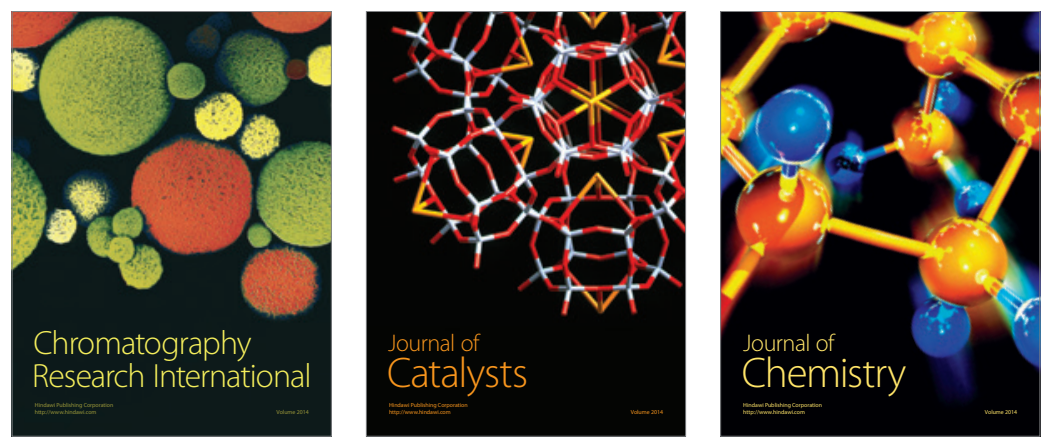
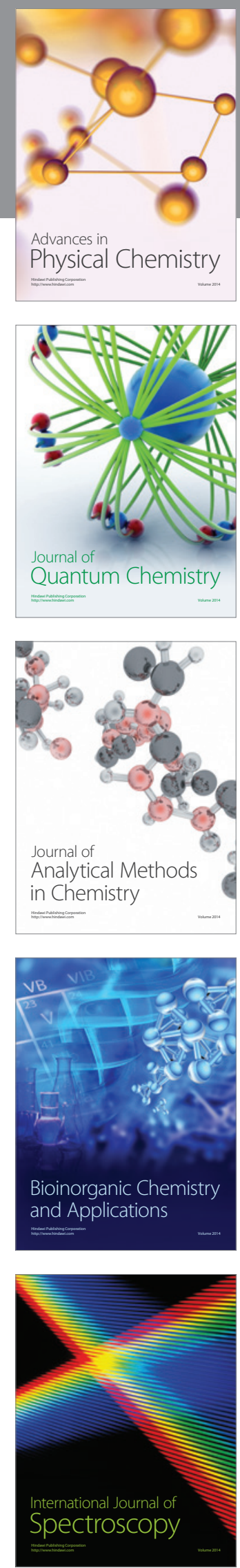